\title{
Effect of Range of Motion Exercise Program on Improving Upper-Arm Region Joints Function for Burned Patients
}

\author{
Asmaa Mohammed Ahmed ${ }^{1}$, Yossef Saleh Hassan ${ }^{2}$, Sahra Zaki Azer $^{3}$ \& Hanan Abd EL-Razik Abd EL-AlI ${ }^{4}$ \\ 1. Demonstrator of Medical Surgical Nursing Department, Faculty of Nursing, Assiut Univeristy, Assiut, Egypt. \\ 2. Professor of Plastic Surgery and Burn Department, Faculty of Medicine, Assiut University, Assiut, Egypt. \\ 3. Assistant professor of Medical Surgical Nursing Department, Faculty of Nursing, Assiut University, Assiut, \\ Egypt. \\ 4. Lecturer of Medical Surgical Nursing Department, Faculty of Nursing, Assiut Univrsity, Assiut, Egypt.
}

\begin{abstract}
Background; Exercise is a key component of burn rehabilitation across all phases of care. This study aimed to; assess burn patient's affected upper-arm region joints function, design and implement range of motion exercise program and evaluate the effect of implementing range of motion exercise program on improving upper-arm region joints function for burned patients. Research design; pre / post test research design was utilized. Setting; the study was conducted in Burn Unit at Assuit University Hospital. Sample; (30) adult patients (male \& female) admitted to the burn unit at Assiut University. Ages ranges from 18 to 65 years. Tools; for data collection included; first tool; Patient's assessment, Second tool: Joints function assessment (pre, post). Results; There was a statistical significance difference as regard patient range of motion on upper-arm region joints in pre / post program implemntation $(\mathrm{p}<0.005)$. Conclusion; upper- arm region joints function was improved among patients who received range of motion exercise program. Recommendation; simple instruction hand book should be available for burned patients.
\end{abstract}

\section{Key work: Burn, Range of Motion Exercise \& Upper-Arm Region.}

\section{Introduction}

A burn is an injury to the tissues of the body caused by heat, chemicals, electric current or radiation. The resulting effects are influenced by the temperature of the burning agent, duration of contact time and type of tissue that is injured (Sharon et al., 2014).

The treatment plan is directly influenced by the depth of the burn and the requirement for surgery. Currently, deep partial thickness and full thickness burn wounds are treated with early excision and grafting. This goal of early excision of damaged tissue and skin grafting is to minimize the secondary problems of scar formation and contracture (Bardon et al, 2008).

Scar contractures are the pathological outcome of excessive scarring and ongoing scar contraction and a well-known complication after burn. Scar contractures impair range of motion (ROM) of joints and thus may limit performing activities of daily living. Considerable clinical and research effort has gone into the prevention and treatment of scar contractures including positioning, splinting, exercise and surgical correction (Oosterwijk et al., 2017).

Range of motion exercise is a key component of burned patient across all phases of care (Paratz et al., 2012). Joint function may diminish as a result of bed rest, decrease protein, altered fluid and electrolyte levels and poor circulation until ultimately contracture occur. Full range of motion joint exercise for all joints begins early in the wound management process and continues at regular daily interval. Active and passive exercises may be combined, depending on the patient's capabilities (Shirley, 2018).

\section{Significance of the study}

From the researcher's experience, it has been observed that burned patients can expose to joint stiffness as a result of burn injury which impair the range of motion, function of joints and negative consequences from it, so range of motion exercise program play an important role for improving function of joints and decrease complications.

\begin{abstract}
Aim of the study
The aim of this study were; 1) assess burn patient's affected upper- arm region joints function, 2) implement range of motion exercise program to improve burn patient upper-arm region joint function, 3 ) to evaluate the effect of range of motion exercise program on improving upper- arm region joints function for burned patients.

Research Hypothesis:

Upper-arm region joints function are improved in burned patients who are receive range of motion exercise

program.
\end{abstract}




\section{Patients and Method}

\section{Research design:}

(Pre / post test) experimental research design was utilized to conduct this study.

\section{Setting:}

The study was conducted in burn unit at Assuit University Hospital.

\section{Sample}

Thirty (30) adult patients (male and female) admitted to burn unit at Assiut University Hospital. Age ranged from 18 to 65 years. A power calculation estimated that in order to detect an effect size of one group (pre / post test) with a p-value $<0.05$ and $80 \%$ power, confidence level 0.95 , so a sample size of (30) patients was needed.

Tools: two tools are used to conduct study:

Tool I: Patient's assessment: this tool consisted of two parts.

Part I: Demographic patient data: It was developed to assess demographic characteristics. It was included age, sex, marital status, level of education and occupation.

Part II: Patient medical data: It was developed to assess past and present medical history. It included cause of burn, degree of burn, percent of burn, first aid, skin graft, joint affected, date of admission and date of discharge.

Tool (II): joints function assessment (pre, post): by using Severity rating contracture scale which was developed by (Schneider et al., 2006). This scale divide contracture into three levels (mild, moderate and severe contracture).

This tool was applied by the researcher by using a goniometer with a standardized technique (Norkin, and White,. 1958). This part was assessed (pre) when the patient admitted in the burn unit and (post) ( $3 \& 6$ ) weeks from patient admission.

\begin{tabular}{|c|c|c|c|c|}
\hline \multicolumn{5}{|c|}{ Severity rating contracture scale (degree) } \\
\hline Joint & $\begin{array}{c}\text { Muscle } \\
\text { action }\end{array}$ & Mild & Moderate & Severe \\
\hline \multirow{4}{*}{ Shoulder } & Flexion & 120 to $180^{\circ}$ & $\begin{array}{l}60 \\
\text { o119。 }\end{array}$ & $\begin{array}{l}\text { Less } \\
60^{\circ}\end{array}$ \\
\hline & Extension & 32 o $50^{\circ}$ & 16 to $31 \circ$ & $\begin{array}{c}\text { Less } \\
16^{\circ}\end{array}$ \\
\hline & Abduction & 120 to $180^{\circ}$ & 60 to $119 \circ$ & $\begin{array}{l}\text { Less } \\
60^{\circ}\end{array}$ \\
\hline & Adduction & 32 o $50^{\circ}{ }^{t}$ & 16 to $31 \circ$ & $\begin{array}{l}\text { Less } \\
16^{\circ}\end{array}$ \\
\hline \multirow{4}{*}{ Elbow } & Flexion & 93 o140。 & 46 to $92^{\circ}$ & $\begin{array}{l}\text { Less } \\
46^{\circ}\end{array}$ \\
\hline & Extension & $\begin{array}{lll}140 & & t \\
093 \circ & \end{array}$ & -46 to $92 \circ$ & $\begin{array}{l}\text { More- } \\
46^{\circ}\end{array}$ \\
\hline & Pronation & 53 o $80^{\circ}$ & 26 to $52 \circ$ & $\begin{array}{l}\text { Less } \\
26^{\circ}\end{array}$ \\
\hline & Supination & 53 o $80^{\circ}$ & 34 to $66^{\circ}$ & $\begin{array}{l}\text { Less } \\
26^{\circ}\end{array}$ \\
\hline
\end{tabular}
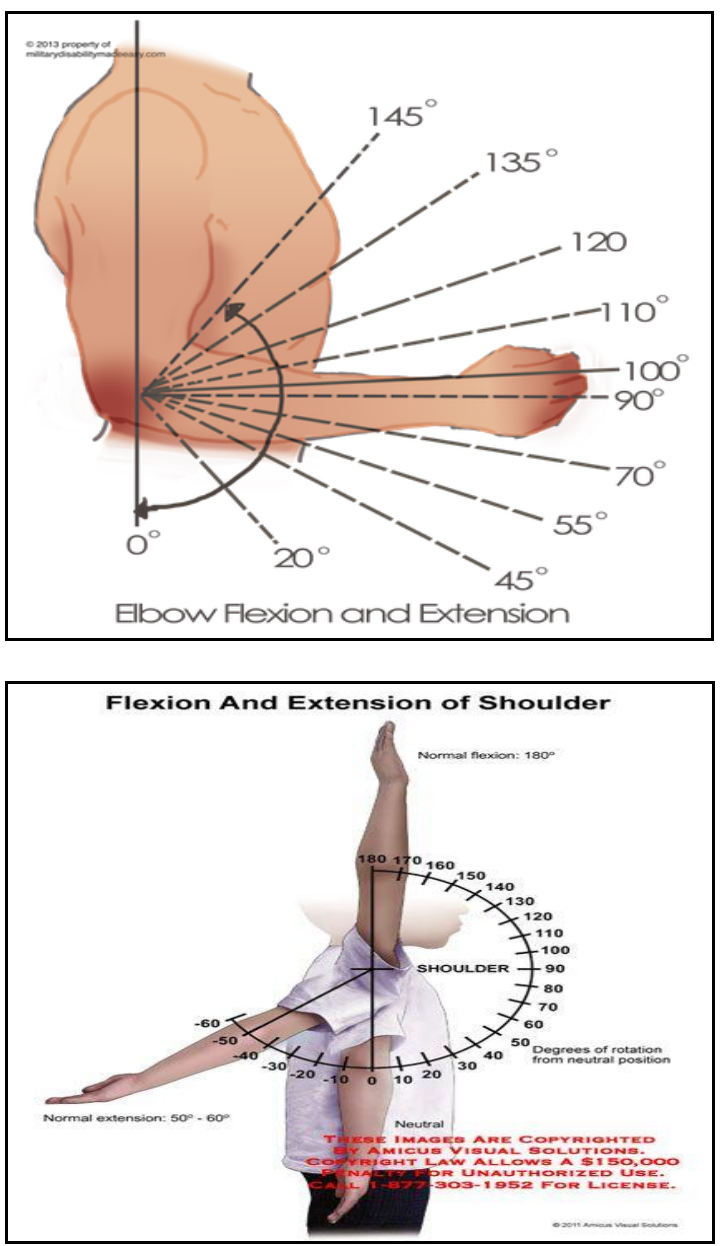

Fig (1): Flexion \& Extension of elbow Fig (2): Flexion \& Extension of shoulder Adopted from https://www.google.com, 2019

Range of motion exercise program for upper-arm region joints function for burned patient:

It was designed to maintain and improves joint function of burned patients. This Range of motion exercises: (ROM) exercises help to keep the muscles and joints of the burned limbs flexible.

Procedure:

This study was carried out in three phases:

\section{I: Preparatory phase}

Tools development

A review of current, past, local and international related literature in the various aspects using books, articles, periodicals, magazines and references were done.

Content validity and reliability

Content validity was done by (5) experts from Medical-Surgical Nursing staff and Medical staff who reviewed the tools for clarity, relevance and comprehensiveness. Minor modifications were done 
and correction was carried out accordingly and then the tools were designed in their final format and tested for reliability. Reliability of the tool was measured by Cronbach's alpha coefficient $(r=0.72)$.

Pilot study

A pilot study on (10\%) (3) Patients were conducted during December, 2018 in order to test the clarity and applicability of the tools. According to this pilot study, the required modifications were made. Those patients who were involved in the pilot study were included in the study.

\section{Implementation phase}

- Once the permission was granted to proceed with the proposed study, the researcher initiated data collection, name of potential patients who have admitted to the unit and who met the criteria were obtained from the medical sheet of the patient. This phase it included two sessions:

- First session, started during 24 hours post admission after fluid resuscitation and wound dressing.

- The researcher greeted the patients, introduced herself and purpose of study was explained to patients who agreed to participate in the study prior to any data collection.

- After taking the patient's oral agreement for voluntary participation in the study, each patient involved in the study was interviewed individually for filling (Tool I).

- The researcher assessed upper-arm region joints function by using (Tool II), this part applied by using the goniometer.

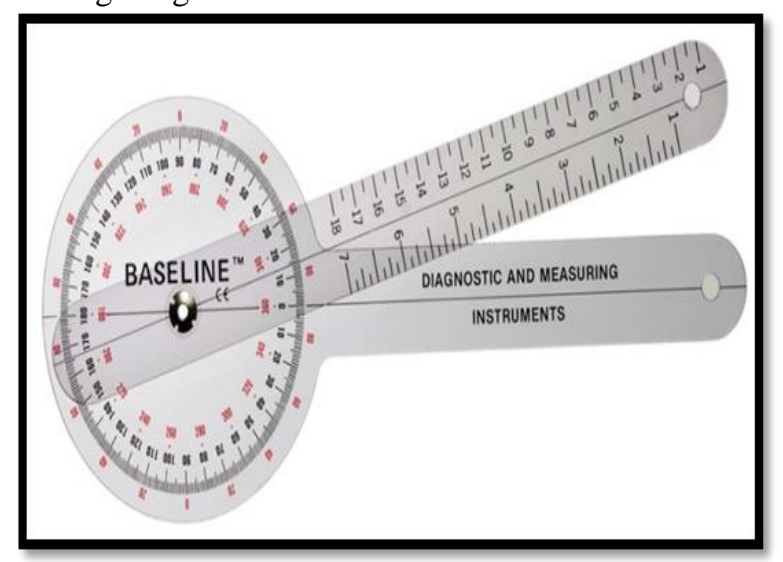

Fig (3): Geniometer, adopted from karmer, 2019

- The researcher explained range of motion exercise program for patient and one family member was present in the session for patient's support and increasing their sense of responsibility. Range of motion exercise program includes the following items: anatomy and function of the skin, definition, causes and degree of burn and complications of burn on joint. The session took about 10-15 minutes.

- Second session: Range of motion exercises can begin immediately (after 24 hours) if the patient has not undergone skin grafting and usually within 1 week after grafting so as not to interfere with graft take. Particular attention must be given to burns that cross joints and burns that result in exposed tendons. These joints are at high risk for contracture development and should receive empirical splinting and ROM. Repeat each exercise 10 times, 3 times aday.

- Exercise could start from major joints (with or without burn injury) using passive, active-assistant and active range of motion training.

- Range of motion exercise can be very painful at the beginning so; mild analgesics are helpful initially to help the patient move and ampulate.

- At the beginning, the most optimal time to do ROM is during dressing changes when the patient is medicated and the bulky dressings are removed and then increase gradually through the day.

- Exercise should be adjusted if unstable vitalsigns (high temperature) and existence of a life threatning condition (presence of bleeding).

- Positioning during exercise is designed based on individual patient needs and medical status dictates.

- Splinting helps maintain anti-contracture positioning particularly for those patients experiencing a great deal of pain and provide a stretched position, which also provides an easier starting point for exercise.

\section{Shoulder ROM}
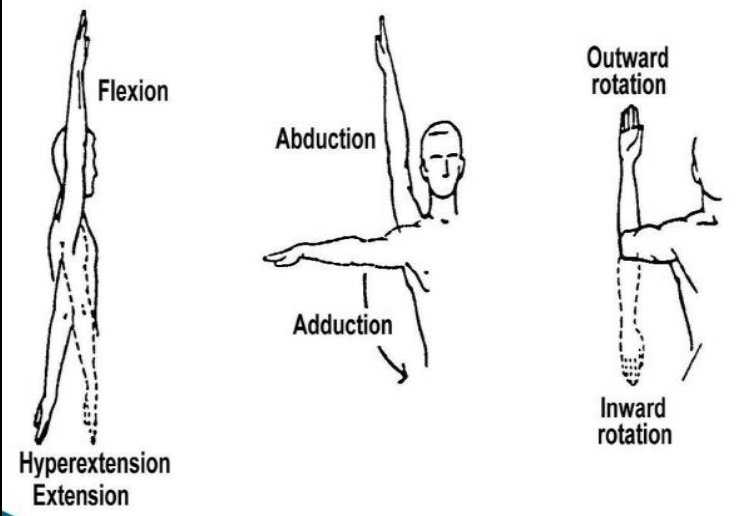

Fig (4): Range of motion exercise for shoulder, Craven and Hirnle, (2009) 


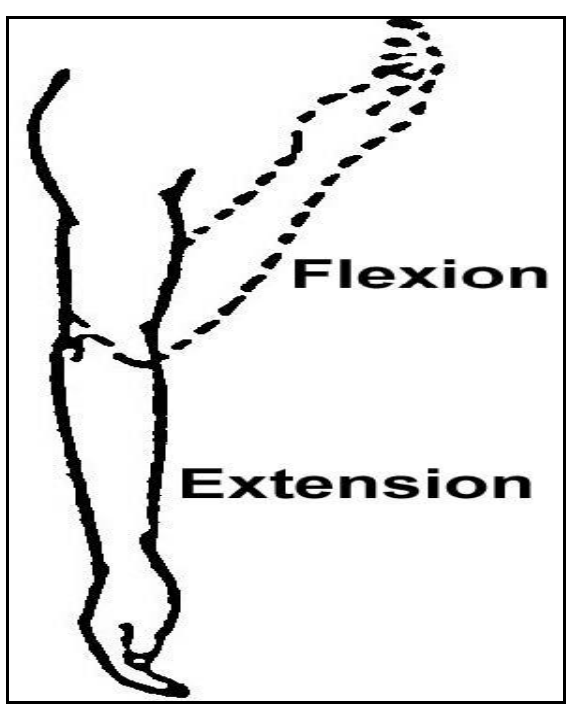

Fig (5): flexion \& extension of elbow, Craven and Hirnle, (2009)

After completing the session there were about 10-20 minutes for explaining and feedback. Reinforcement was performed according to patient's needs to ensure their understanding.

- Each patient obtained a hard copy of the booklet also the researcher used pictures to enhance patient's understanding and helped them to retain the learned material.

- The collection of data lasted through the period from January 2019 to June 2019.

- III- Evaluation phase:

In this phase the researcher assessed upper - arm region joint function using (Tool II) post three (3) and post six (6) weeks from patient admission.

\section{Ethical Consideration}

- Research proposal was approved from Ethical Committee in the Faculty of Nursing.

- There is no risk for study subject during application of the research.

- The study was following common ethical principles in clinical research.

- Oral consent was obtained from patient or guidance that is willing to participate in the study, after explaining the nature and purpose of the study.

- Confidentiality of the subject data was assured.

- They were informed that participation is voluntary and that they could withdraw at any time of the study.

- Anonymity was considered during collection of data.

\section{Statistical analysis}

Data entry was done using compatible personal computer by the researcher. All data was entered into statistical packages for the social sciences (SPSS) version 22.0 software for analysis and excel for figures. The content of each tool was analysed, categorized and then coded by the researcher. Categorical variables were described by number and percent, where continuous variables described by mean and standard deviation (Mean, SD). Chi-square test and fisher exact test used to compare between categorical variables where compare between continuous variables by t-test and anova test. A twotailed $\mathrm{p}<0.05$ was considered statistically significant. 


\section{Results}

Table (I): Frequency distributions of studied patients as regarding to their demographic characteristics $(n=30)$.

\begin{tabular}{|c|c|c|}
\hline Variables & $(n=30)$ & $\%$ \\
\hline \multicolumn{3}{|l|}{ Age } \\
\hline Mean \pm SD(range) & \multicolumn{2}{|c|}{$31.3 \pm 13.1(18-65)$ years } \\
\hline \multicolumn{3}{|l|}{ Length of hospital stay } \\
\hline Mean \pm SD $($ range $)$ & \multicolumn{2}{|c|}{$25.8 \pm 15.4(3-72)$ days } \\
\hline \multicolumn{3}{|l|}{ Sex } \\
\hline Male & 17 & 56.7 \\
\hline Femal & 13 & 43.3 \\
\hline \multicolumn{3}{|l|}{ Marital status } \\
\hline Single & 12 & 40.0 \\
\hline Married & 16 & 53.3 \\
\hline Widow & 2 & 6.7 \\
\hline \multicolumn{3}{|l|}{ Educational level } \\
\hline Illiterate & 9 & 30.0 \\
\hline Read and write & 2 & 6.7 \\
\hline Preparatory school & 4 & 13.3 \\
\hline Secondary school & 13 & 43.3 \\
\hline University education & 2 & 6.7 \\
\hline \multicolumn{3}{|l|}{ Occupation } \\
\hline Farmer & 1 & 3.3 \\
\hline Student & 5 & 16.7 \\
\hline Machinery work & 11 & 36.6 \\
\hline Housewife & 13 & 43.3 \\
\hline
\end{tabular}

Table (2): Frequency distribution of studied patients as regarding to their medical data $(n=30)$.

\begin{tabular}{|c|c|c|}
\hline Variables & $(n=30)$ & $\%$ \\
\hline \multicolumn{3}{|l|}{ 1.Past medical history: } \\
\hline Diabetes mellitus & 2 & 6.7 \\
\hline Hypertension & 3 & 10.0 \\
\hline Renal disease & 0 & 0.0 \\
\hline \multicolumn{3}{|l|}{ Causes of burn: } \\
\hline \multicolumn{3}{|l|}{ Thermal } \\
\hline Flame & 24 & 80.0 \\
\hline Scald & 4 & 13.4 \\
\hline Flashburn & 1 & 3.3 \\
\hline Electrical & 1 & 3.3 \\
\hline \multicolumn{3}{|l|}{ Degree of burn } \\
\hline Superficial second degree & 12 & 40.0 \\
\hline Deep second degree & 15 & 50.0 \\
\hline Third degree burn & 3 & 10.0 \\
\hline \multicolumn{3}{|l|}{ Percent of burn (TBSA) } \\
\hline Mean \pm SD(range $)$ & \multicolumn{2}{|l|}{$20.3 \pm 10.7(5-50)$} \\
\hline \multicolumn{3}{|l|}{ Skingraft } \\
\hline Yes & 6 & 20.0 \\
\hline No & 24 & 80.0 \\
\hline \multicolumn{3}{|l|}{ First aid } \\
\hline Yes & 1 & 3.3 \\
\hline No & 29 & 96.7 \\
\hline
\end{tabular}


Table (3): Distribution of patients as regard to assessment of upper - arm region joint function affected pre / post ( 3 and 6 weeks) after implementation of range of motion exercise program $($ no. $=30)$.

\begin{tabular}{|l|c|c|c|c|}
\hline \multirow{2}{*}{ Joints function affected } & $\begin{array}{c}\text { Pre program } \\
\text { (on admission) }\end{array}$ & $\begin{array}{c}\text { Post (after 3 } \\
\text { weeks) }\end{array}$ & $\begin{array}{c}\text { Post (after 6 } \\
\text { weeks) }\end{array}$ & \multirow{2}{*}{ P.value } \\
\cline { 2 - 5 } & Mean \pm SD & Mean \pm SD & Mean \pm SD & \\
\hline Shoulder & $158.33 \pm 7.64$ & $148.33 \pm 7.64$ & $176.67 \pm 2.89$ & $0.005^{* *}$ \\
\hline Flexion & $45 \pm 5$ & $40 \pm 2$ & $50 \pm 0$ & $0.022^{*}$ \\
\hline Extension & $151.67 \pm 7.64$ & $133,33 \pm 15.28$ & $175.67 \pm 5$ & $0.007^{* *}$ \\
\hline Abductions & $50 \pm 0$ & $50 \pm 0$ & $50 \pm 0$ & -- \\
\hline Adduction & \multicolumn{5}{|l|}{} \\
\hline Elbow & $139.27 \pm 1.75$ & $128.6 \pm 13.96$ & $134.77 \pm 13.39$ & $0.042^{*}$ \\
\hline Flexion & $0 \pm 0$ & $4.33 \pm 16.78$ & $0 \pm 0$ & 0.376 \\
\hline Extension & $80 \pm 0$ & $77.67 \pm 6.78$ & $78.33 \pm 6.45$ & 0.482 \\
\hline Pronation & $80 \pm 0$ & $73.47 \pm 7.6$ & $77.17 \pm 7.84$ & $0.025^{*}$ \\
\hline Supination &
\end{tabular}

- One way Anova, * Significant SD difference at $p$. value $<0.05$, ** Significant difference at $p$. value $<0.01, N . S=$

Not significant at P.value $>0.05$.

Table (1): Illustrate that mean age of patients was $(31.3 \pm 13.1)$ years old, more than half of them were males. Regarding to length of hospital stay it was found that the mean hospital stay of studied patients was $(25.80 \pm 15.42)$ days. Also the highest percentage of the studied patients was married and secondary school $(53.3 \%, 43.4 \%)$ respectively. As regard occupation it was found that the highest percentage $(43.3 \%)$ was house wife.

Table (2): Clarifies that lowest percentage of the studied patients have diabetes mellitus and hypertension $(6.7 \%, 10 \%)$ respectively. The majority $(80 \%)$ of the studied patients were flame burn causes, followed by scald burn (13.4) and (50\%) of the studied patient were represented by second degree burn. As regard to percent of burn; the mean percent of burn of studied patient was $(20.3 \pm 10.7)$.

Table (3): Illustrated that; there was a statistical significance difference as regard patient joint function on different upper- arm region joints in pre $/$ post implementation of range of motion exercise program.

\section{Discussion}

Regarding demographic characteristics of the patients; the current study revealed that; the majority of studied patient their age more than thirty-one. These findings supported by Taghavi et al., (2009), Alavi et al., (2012) \& Honnegowda et al., (2019) who reported that the mean age of patients were more than thirty-one.

As regard to hospital stay, the results of data collected in this study showed that the mean hospital stay of studied patients was twenty-five days, this result agreed with Odoch et al., (2016) who stated that the mean hospital stay was more than twentyfour days. But this study disagreed with Saaiq \& Ashraf, (2014) who stated that hospital stay of patients ranged from one to thirty-seven days with a mean of seven days. From the researcher opinion; the difference on the length of hospital stay between patients depending on various factors such as age, cause of burn, degree of burn and also wound healing process

The current study revealed that, more than half of patients were male, this result was congruent with Daffue et al., (2018) Faisal et al., (2016) \& Also in line with Gupta et al., (2011) who stated in his study " A clinico-epidemiologic study of patients with burn injuries at a tertiary care hospital in Punjab, India " out of patients, more than half were males and less than half were female.

And also disagree with a study conducted at the burn unit of Al Ahrar Hospital in Zagazig city, Sharkia Governorate by Magdy et al., (2016) entitled as "An interventional study to decrease healthcare associated burn wound infections in the burn unit of Al Ahrar Hospital in Zagazig city, Sharkia Governorate". This revealed that more than half of studied patient was female.

In relation to marital status and occupation, the present study revealed that the highest percentage of studied patients was married, housewives and secondary school. This study finding was in line with a study conducted at burn and plastic surgery department at Assuit University Hospital by Ahmed, (2018) entitled as"Risk factors of abdominal compartment syndrome during resuscitation phase of burned patients" which revealed that the highest 
percentage of patients were married, housewives and secondary school.

From the researcher opinion; a higher number of female sustained burn injuries at home compared with male sustain injuries outdoors. Cooking appliance was the most common cause of injury in females and this account for unsafe cooking and this related to lack of awareness about self-precautions from burn hazardous at homes.

Regarding medical data; the result of the present study revealed that the lowest percentage of studied patients had diabetes mellitus and hypertension. These finding supported by Maghsoudi et al., (2008) who stated that the lowest percentage of burns patients had diabetes. Also in an agreement with result Dolp et al., (2019) who mentioned that the lowest percentage of burn patients admitted between 2006 and 2016 have diabetes mellitus.

The current study; revealed that the majority causes of burn was flame (thermal burn) among adult, followed by moist (thermal). This study in line with Khashaba et al., (2012), Tripathee and Basnet, (2017), who stated that flame burns were the most common cause of burn injuries, followed by scalds. Scalds were most common in children. Also agree with a study conducted by Faris and Al Naser, (2019) entitled as "Epidemiological characteristics of burn injuries in Iraq: A burn hospital-based study" which mentioned that more than two third of patients were burned by flame and less than one third were burned by hot fluid.

On the other hand this finding contradicted by Hosseini et al., (2017) who demonstrated that the most common cause of burn were hot liquids, gas explosion, and fire.

Study result represented that, the highest percentage of the studied patient had second degree burn and the lowest percentage have third degree burn. Hassan et al., (2008) reported that more than half of patients had second-degree than third degree burns. All the cases had history of burns in the upper extremities, with more than half presenting burns only in the hands and/or wrists and less than quarter only in the forearm.

Likewise Al Laham et al., (2015) \& Melake et al., (2015) were in the same line as they pointed that the majority of burnt patient injuries more than thirds were of the second degree, whereas less than one quarter has third degree burn and the lowest percentages were of the first degree.

The present finding of this study showed that; the percent of burn (TBSA) ranges from (5-50\%) with a mean $(20.3 \pm 10.7)$. these finding was supported by Chien et al., (2003) who reported that the mean percent total body surface area (\% TBSA) for adults was (19\%), and for young children was (12\%). Also the previous finding was supported by Hosseini et al., (2017) who stated about two-third of the patients were male. The majority of burns were less than thirty percentage of total body surface area.

Regarding effect of range of motion exercise program; the result of the present study reported that there was a statistical significant difference as regard patient range of motion in different upper limbs joint pre/post implementation of program. Hoffman et al., (2000) who conducte a clinical trial on burn patients and applied different techniques to reduce pain and prevent contractures in sub acute stage of rehabilitation. They concluded that the early passive range of motion exercise has a significant role in pain management and decrease contracture.

In accordance with our results Flintham \& Callaghan, (2005) support this finding as they stated that exercises were effective on improvement of joint movement and improvement of skin movement. These results were in line with Zoubine et al., (2007) who reported that physiotherapy program in patient with hands burn considerably reduced complications of burning particularly contracture.

Also this finding agree with Grisbrook et al., (2012) as they showed that effect of exercise education on patients with burns had positive effect on promotion of physical health level and also improvement of their life quality.

Likewise Ardebili et al., (2014) supported the result as they demonstrated that significant improvements in range of motion and hand function balance from admission to discharge.

\section{Conclusion}

The study findings supported all research hypotheses as it had been proven that there an improving on the function of joint on the six weeks from admission; in spite of decline on mean range of motion at three weeks (normal component of the healing process) .Joint function was improved among patients who received rehabilitation exercise program.

\section{Recommendations:}

Simple instruction hand book should be available for burned patients.

\section{References}

1. Ahmed Z., (2018): Risk Factors of Abdominal compartment syndrome during Resuscitation Phase of Burned patient.Master degree, Critical department, Faculty of nursing, Assiut University.

2. Al Laham N., Elmanama A., \& Tayh G., (2015): Possible Risk Factors Associated with 
Burn Wound Colonization in Burn Unit of Gaza Strip Hospitals, Palestine, Annals of Burns and Fire Disasters, vol. (26), No. (2), P.p68-75.

3. Alavi C., Salehi S., Tolouei M., Paydary K., Samidoust P., \& Mobayen M., (2012): Epidemiology of Burn Injuries at a Newly Established Burn Care Center in Rasht, Trauma Mon,Vol.(17), No. (3), P.p 341-6.

4. Ardebili M., Manzari S., \& Bozorgnejad M., (2014): Effect of educational program based on exercise therapy on burned hand function, Vol. (3), No. (1), P.p 39-46.

5. Bardon J., Mary C., \& Damon C., (2008): Orthoses for the burned hand, upper limb orthoses, Atlas of Orthoses and Assistive Devices, chapter (13), $4^{\text {th }}$ (ed), Mosby Elseiver, P.220.

6. Chien W., Pai L., Lin C., \& Chen H., (2003): Epidemiology of hopitalized burns patients in tiwan, Vol. (39), No.(6), P.p 582-588.

7. Craven F., \& Hirnle J., (2009): Mobility and body mechanics, Human Health and Function, Fundamental of Nursing, chapter (35), $5^{\text {th }}(\mathrm{ed})$, by Williams and wilikims inc, P.779 .

8. Daffue B., Moolman D., Ferreira S., Roos L., Schoeman L., Smit S., \& Joubert G., (2018): the causes of burn wounds among adult patients treated at Pelonomi Tertiary Hospital, Bloemfontein, general surgery, Vol. (56), No. (3), P.p 31-36.

9. Dolp R., Rehou S., Pinto R., Trister R., \& Jeschke G., (2019): The effect of diabetes on burn patients: a retrospective cohort study, vol. (23), No. (1), P.p 1-10.

10. Faisal A., Amjad A., \& Zehra N., (2016): Impact of facial burn injury on self esteem of burn patients- a hospital based study from Karachi. J Dow Uni Health Sci, vol (10), No (1), P.p 25-30.

11. Faris H., \& Al Naser K., (2019): Epidemiological characteristics of burn injuries in Iraq: A burn hospital-based study, Burns, Vol. (45), No. (2), P.p 479-483.

12. Flintham K., \& Callaghan M., (2005): the effect of physiotherapy on hypersensitive post-operative scars, J physiotherapy, vol. (85), P.p 1301-17.

13. Grisbrook T., Reid S., Edgar D., Wallman K., Wood F., \& Elliott C., (2012): Exercise training to improve health related quality of life in long term survivors of major burn injury, Vol. (38), No. (8), P.p 1165-37.

14. Gupta K., Uppal S., Garg R., Gupta A., \& Pal R., (2011): A clinico-epidemiologic study of 892 patients with burn injuries at a tertiary care hospital in Punjab, India, J Emerg Trauma Shock, Vol (4), No (1), P.p 7-11.
15. Hassan Z., Mullins R., Alam B., \& Mian M., (2008): Carpal Tunnel Syndrome Following Burn, Annals of Burns and Fire Disasters, Vol.(20), No.(3), P.p 153-155.

16. Hoffman H., Patterson D., Carrougher G., (2000): use of virtual reality for adjunctive treatment of adult burn pain during physical therapy: a controlled study, Vol. (16), No. (3), P.p 244-50.

17. Honnegowda M., Kumar P., Udupa P., \& Rao P., (2019): Epidemiological study of burn patients hospitalized at a burns center, Manipal. Int wound, Vol. (16), No. (1), P.p 79-83.

18. Hosseini S., Rashtchi V., Kamali K., \& Moghimi M., (2017): Epidemiology and outcome of 2,590 burned patients in Northwest Iran. Annals of Burn and Fire Disasters, Vol. (30), No. (2), P.p 85-90.

19. Karmer E., (2019): How to use a Geniometer. Available at http:// www.wiki how.com/ use -aGeniometer.

20. Khashaba H., Al-Fadhli A., Al-Tarrah K., Wilson Y., \& Moiemen N., (2012): Epidemiology and Outcome of Burns at the Saud Al Babtain Burns, plastic surgery and reconstructive center, Kuwait: our experience over five years (from 2006 to 2010), A annals of Burns and Fire Disasters, Vol. (25 ), No (4), P.p 178-187.

21. Magdy H., El-Maghawry M., El Nem W., AbdAllah Sherif N., \& Hagag S., (2016): An interventional study to decrease healthcare associated burn wound infections in the burn unit of Al Ahrar Hospital in Zagazig city, Sharkia Governorate, Vol. (5), No. (3), P.p 566-578.

22. Maghsoudi H., Aghamohammadzaden N. and Khalili N., (2008): Burns in diabetic patients, international Journal of diabetes in developing countries, vol. (28), N. (1), P.p19-25.

23. Melake N., Eissa N., Keshk T., \& sleem A., (2015): Prevalence of multidrug- resistant bacteria isolated from patients with burn infection, Vol. (28), No. (3), P.p 677-684.

24. Norkin C., \& White D., (1958): Measurement of Joint Motion: A Guide to Goniometry. Philadelphia: FA Davis; 1985.

25. Odoch R., Atuhairwe C., Amogin D., Titus L., Agaba E., \& Nabankema E., (2016): Predictors of Length of Hospital Stay among Burns Patients in Mulago National Referral Hospital, KampalaUganda, Journal of Health, Medicine and Nursing, Vol.(29), P.p 32-39 .

26. Oosterwijk A., Mouton L., Schouten H., Disseldorp L., van der Schans C., \& 
Nieuwenhuis M., (2017): Prevalence of scar contractures after burn: A systematic review, Vol. (43), No.(1): P.p 41- 49.

27. Paratz J., Stockton K., Plaza A., Muller M., \& Boots R., (2012): Intensive exercise after thermal injury improves physical, functional, and psychological outcomes, Vol. (73), P.p 186 - 194.

28. Rreca S., Hysena H., Martina M., Murtezani A., Ibrahimi-Kacuri D., Haxhiu B., \& Buja Z., (2015): Outcome of physical therapy and splinting in hand burn injury. Our last four year's experience, vol. (27), No. (6), P.p372-376.

29. Saaiq M., \& Ashraf B., (2014): Epidemiology and Outcome of Self-Inflicted Burns at Pakistan Institute of Medical Sciences, Islamabad, World J Plast Surg, vol. (3), No. (2), P.p 107-114.

30.Schneider J., Holavanahalli R., Helm P., Goldstein R., \& Kowalske K., (2006): Contractures in burn injury: defining the problem. J Burn Care, Vol. (27), No.(4), P.p 508-514.

31. Sharon L., Shannon R., Margarel M., \& Linda B., (2014): Rehabilitation phase, MedicalSurgical Nursing: Assessment and management of clinical problems, Section (4), $9^{\text {th }}$ (ed), Mosby Elsevier, P.p 450, 489.

32. Shirley P., (2018): Prevention, Intervention, and outcome: Rehabilitation nursing, chapter (31), $4^{\text {th }}$ (ed), Mosby Elsevier, P. 73.

33. Tripathee S., \& Basnet J., (2017): Epidemiology and outcome of hospitalized burns patients in tertiary care center in Nepal: Two year retrospective study, vol. (1), No. (1) P.p 16-19.

34. Zoubine N., Okhovation F., (2007): A comparative between two burn rehabilitation protocols, Burns, vol. (34), No. (2), P.p 429-434. 